\title{
SERVICIO DOMÉSTICO Y TRABAJO DE CUIDADOS. HACIA LA PRIVATIZACIÓN DEL CUIDADO FAMILIAR
}

\author{
Domestic service and care work. \\ Towards the privatisation of family care
}

RAQUEL MARTÍNEZ BUJÁN*

\begin{abstract}
Resumen
Este artículo se inscribe en el estudio de la inmigración y el envejecimiento de la población desde una perspectiva asistencial que estudia a la población inmigrante como un recurso para cuidar a personas mayores. Desde esta aproximación, la migración internacional en España (y en los países de Europa del sur) es utilizada para cubrir las debilidades de la protección social a la dependencia y llenar los huecos que la incorporación laboral de las mujeres nativas ha dejado en sus hogares. Este mercado laboral de cuidados encuadrado, en la mayor parte de los casos, en el interior del servicio doméstico se ha llegado a convertir en nuestro país en un verdadero nicho laboral para las mujeres inmigrantes (fundamentalmente latinoamericanas) y, en la actualidad, se ha configurado como la principal vía de externalización y mercantilización del trabajo familiar de cuidados. Mediante un análisis del modelo migratorio, de la política social y del panorama laboral en Galicia y Navarra, se estudian de manera comparativa las causas del surgimiento de este sector de cuidados, el papel que desempeñan las mujeres inmigrantes en su aparición, la ubicación de esta actividad en el servicio doméstico, la incidencia de las nuevas tendencias privatizadoras de la política social y las implicaciones de algunos cambios sociales y demográficos como el envejecimiento de la población y la inserción de la mujer nativa al mercado laboral formal.
\end{abstract}

\footnotetext{
* Raquel Martínez Buján Universidade da Coruña

Facultad de Sociología

Campus de Elviña, s/n. 15071 La Coruña

Teléfono: 629358513

rmbujan@udc.es
} 
Palabras clave: inmigración, servicio doméstico, mujeres, personas mayores, cuidados.

\begin{abstract}
This paper studies immigration and the ageing of the population in terms of immigration as a resource to care for elderly persons. In this regard, international migration in Spain and other Southern European countries is used to cover care-related shortfalls in social protection, filling the gap left at home by native women entering the workforce. In Spain, this job market of care, which in most cases forms part of domestic service, has become a veritable niche for immigrant women (mainly from Latin America) and is currently the main way in which family care is outsourced and commodified. The migratory model, social policy and the employment situation in Galicia and Navarre are analysed in a comparative study of the causes of this growth in the care sector, the role that immigrant women play in it, how this activity fits within domestic service, the impact of the new trend towards privatising social policy, and the implications of certain social and demographic changes, such as the ageing of the population and native women joining the formal labour market.
\end{abstract}

Keywords: immigration, domestic service, women, elderly persons, care.

\title{
1. Introducción
}

«De nada han servido los reproches de la Iglesia, el rechazo de sindicatos y oposición, las preocupaciones del presidente italiano, el ex comunista Giorgio Napolitano, y las dudas de muchos juristas sobre su constitucionalidad: para los 650000 inmigrantes indocumentados, que se estima residen en Italia, su presencia en el país a partir de ahora basta para convertirlos en criminales. Ayer mismo se producían las primeras detenciones en varias ciudades.

La medida, contenida en el paquete de seguridad impulsado por el ministro del Interior, Roberto Maroni -miembro destacado de la Liga Norte, el partido que ha hecho de la lucha contra la inmigración el pilar de su proyecto político-, cumple la promesa que el Gobierno de Silvio Berlusconi realizó hace un año en su primer Consejo de Ministros.

Pero se trata de un cumplimiento sólo a medias. El Ejecutivo acaba de aprobar un decreto que, según cálculos oficiales, permitirá la regularización de al menos 300000 sin papeles. Y lo ha hecho a petición de miembros de la coalición en el poder que, en vísperas de la entrada en vigor de la ley antiinmigración, han puesto encima de la mesa el problema que supondría la criminalización de decenas de miles de badanti: personas que cuidan de mayores y enfermos y atienden a miles de familias italianas en sus hogares.

“¿Qué les decimos a las familias?”, se preguntó el viceministro de origen democristiano Carlo Giovanardi, quien propuso por primera vez esta regularización. Giovanardi suscitó recelos entre sus correligionarios del Pueblo de la Libertad, el partido de Berlusconi, y la ira de sus socios de la Liga Norte. Pero al final, la regularización masiva de cuidadores y personal doméstico ha sido aprobada por decreto esta misma semana. A partir del 1 de septiembre, estos trabajadores podrán 
ver legalizada su situación laboral tras el pago de una tasa, como cotizaciones atrasadas a la Seguridad Social, que espera ingresar unos 1300 millones de euros.

Se repite ahora en Italia lo ocurrido en 2002, cuando antes de que entrara en vigor una restrictiva Ley de Extranjería, el Gobierno de Berlusconi regularizó a 650000 sin papeles. "Fue la mayor regularización aprobada en Italia", recuerda Tito Boeri, economista y profesor de la Universidad Bocconi de Milán, quien subraya que el Ejecutivo ha tenido que responder de nuevo con una medida de emergencia. Porque el colectivo de badanti "representa para muchas familias el único recurso para tapar los huecos del sistema de protección social".

Pero aun con esta regularización selectiva, los problemas no parecen haberse resuelto. Porque la criminalización de los inmigrantes indocumentados también afecta a otros sectores productivos, como la construcción o la agricultura. Así lo aseguraban muchos representantes de los partidos integrados en el Gobierno, encabezados por el ministro para el Desarrollo, Claudio Scajola, quien, en el Corriere della Sera, se ha mostrado a favor de "solucionar las situaciones más delicadas, que no tienen nada que ver con la criminalidad". Sus palabras han levantado una polvareda política en Italia. La Liga Norte ha replicado "que no hay ninguna posibilidad de [aprobar] otras regularizaciones". Mientras, dirigentes del partido de Berlusconi han insistido en que se trata de una necesidad vital para las empresas. Ayer fue Fini, desde Bélgica, quien recordó a sus aliados políticos "que hay que respetar a los trabajadores aunque no tengan papeles".

"El debate abierto y la decisión de regularizar a las cuidadoras es la demostración de que las políticas del Gobierno sobre la inmigración han fallado y están destinadas a fallar", argumenta el profesor Boeri, "ya que las empresas del noroeste de Italia [el feudo político de la Liga Norte] necesitan mano de obra que las leyes sobre la inmigración hacen inaccesible".

El cupo de entrada de inmigrantes extracomunitarios ofreció 170000 puestos de trabajo en 2007. Se recibieron casi 700000 solicitudes. "Según la ley, son los empresarios quienes tienen que presentar una demanda [de permiso de trabajo] para inmigrantes que supuestamente están en el extranjero. Pero la realidad es que ya se encuentran aquí", explica el jurista de la Universidad de Palermo Fulvio Vassallo Paleologo. Para este especialista de legislación de extranjería, el Gobierno "criminaliza a los inmigrantes" con las nuevas normas y abre además "una situación imposible de sostener por los atascados tribunales italianos".

Pero es también una medida para obviar las limitaciones a las expulsiones previstas en la normativa de la Unión Europea. "La llamada directiva de la vergüenza, la directiva de retorno aprobada en diciembre de 2008, con todos sus defectos prevé garantías para los inmigrantes frente a la expulsión. Salvo que se haya cometido un delito", dice Vassallo. Pero en Italia ya es delito vivir sin papeles.

El País, 9 de agosto de 2009

En un contexto de crisis económica se convierten en ruidosas voces los rumores que ya desde hace tiempo solicitaban un endurecimiento del control migratorio, de la regulación de los flujos y de la deportación de inmigrantes clandestinos. Este discurso ha estado muy presente en el ambiente político, 
mediático y social, que achaca la inestabilidad económica y el aumento del desempleo al asentamiento de población extranjera. El debate ha cobrado un cariz especial en los países de Europa del sur cuyos regímenes migratorios se han caracterizado por la recepción de una elevada migración irregular «tolerada», combinada con un sistema de control fronterizo ineficaz que traduce su incompetencia en repetidos programas de regularización.

España ha experimentado uno de los procesos migratorios más intensos de los países desarrollados. Las fuentes de información demográfica tanto internacional (Organización de Naciones Unidas, OECD, Eurostat) como nacional (Instituto Nacional de Estadística) señalan que es el segundo país del mundo receptor de inmigrantes en términos absolutos (Laparra, 2008). Tal es así que si en el año 2000 el número de población extranjera se situaba en las 637085 personas, en la actualidad la cifra alcanza 5268764 personas $^{1}$, es decir, se ha multiplicado por diez en tan sólo ocho años. Este espectacular vigor de los flujos migratorios se ha producido también en Italia, Portugal, Grecia, Chipre o Malta (países con un saldo migratorio superior al de la media europea) y está relacionado con un ciclo económico positivo y con una necesidad laboral. Esta paradoja entre el mercado como demandante de mano de obra y el Estado como instrumento de control (Finotelli, 2008) se representa claramente en la actividad del sector doméstico de cuidados.

El servicio doméstico es, según la Encuesta de Población Activa (ofrecida por el Instituto Nacional de Estadística), la actividad laboral en la que se ha producido una mayor extranjerización. La incidencia de la población inmigrante en esta actividad es nueve veces mayor que entre la población nativa ${ }^{2}$. El enclaustramiento del colectivo foráneo en unas determinadas actividades minimiza la competencia laboral con respecto a la población autóctona. De ahí que la tasa de desempleo de los nativos haya descendido incluso en los años de mayor afluencia migratoria: pasó de un 13,7 \% en el año 2000 a un $10,8 \%$ en el $2004^{3}$. España es un país atractivo de inmigración (al igual que

1. Cifra del 1 de enero de 2008 del Padrón Municipal de Habitantes.

2. La incidencia se ha calculado dividiendo el porcentaje de población nativa entre el porcentaje de población inmigrante ocupada en una serie de actividades. Entre las que se encuentra una distancia más elevada, es decir, en las que existe una sobrerrepresentación de la población inmigrante son: la agricultura (incidencia $=1,5$ ), la construcción (incidencia $=1,9$ ), la restauración (incidencia $=2,4$ ) y el servicio doméstico (incidencia= $8,6)$.

3. Además, tanto en épocas de crisis como de bonanza, el desempleo afecta en mayor medida al colectivo extranjero que al autóctono. Mientras que la media de la tasa de paro en el periodo 2003-2007 se situó en un 9,2 \% para la población nativa, entre el colectivo inmigrante alcanzó la cifra de un 13,3\%. 
otros países de Europa del sur) pero no por su capacidad de acogida ni por su Estado de Bienestar, sino porque es bien sabido que se trata de una región en la que es fácil acceder a un empleo, con un importante sector de economía sumergida, fundamental para encontrar un trabajo en el comienzo del ciclo migratorio.

El sector doméstico de cuidados se ha configurado precisamente como una de esas actividades en las que la población extranjera, principalmente femenina y latinoamericana, pueden insertarse al cabo de pocos meses de su llegada a España. De hecho, una de las principales características de la composición de los actuales flujos migratorios que llegan a nuestro país es su tendencia a la feminización y a la latinoamericanización (Izquierdo et al., 2003). A 1 de enero de 2008, según los datos del Padrón Municipal de Habitantes, residen en España alrededor de 2500000 de mujeres extranjeras, siendo el colectivo latinoamericano el de mayor presencia de mujeres. Este número cuadruplica la cifra de seis años atrás. En el 2001, la presencia del colectivo femenino foráneo alcanzaba las 650000 personas. Esta elevada necesidad de mano de obra femenina en el mercado laboral español va a estar determinada por la demanda de trabajadores dedicados a servicios orientados a las familias. Esto es, empleadas de hogar transformadas en niñeras y cuidadoras de personas mayores.

Según los últimos datos de afiliación a la Seguridad Social ofrecidos por el Ministerio de Trabajo (diciembre 2008), el 56,6 \% de las personas incluidas en el Régimen Especial de Servicio Doméstico es extranjero. La aparición de esta extranjerización en el servicio doméstico ha estado vinculada al envejecimiento de la población y a la incorporación de la mujer nativa al mercado laboral formal. El cuidado de personas dependientes, principalmente ancianos, por parte de empleadas de hogar inmigrantes se ha convertido en el primer trabajo que han encontrado a su llegada a España.

Este artículo tiene como objetivo principal analizar las características del sector de cuidados relacionado con la asistencia a personas mayores y delegado a las mujeres inmigrantes en el ámbito doméstico, haciendo especial hincapié en cómo se ha procedido a privatizar el trabajo familiar de cuidados y cuáles son las características e implicaciones de este sector de actividad tanto para las cuidadoras como para las personas mayores.

La metodología utilizada es cualitativa y forma parte de la elaborada para la redacción de mi tesis doctoral («Bienestar y cuidados: El Oficio del Cariño. Mujeres inmigrantes y mayores nativos»). El trabajo de campo efectuado está basado en entrevistas en profundidad dirigidas a tres colectivos: mujeres inmigrantes cuidadoras de ancianos (30 entrevistas), familias empleadoras 
(20 entrevistas) y técnicos de asociaciones, ONGs y otras instituciones con una bolsa de empleo para el trabajo de cuidados ofertado a extranjeros (20 entrevistas). El espacio geográfico de la investigación se circunscribe a la ciudades de La Coruña y Pamplona, lugares en los que se ha realizado el trabajo de campo.

\section{El incumplimiento de la protección social}

Con un 16,5 \% de personas que sobrepasan los 65 años, España se ha convertido en un país envejecido. La asociación entre edad y ausencia de autonomía repercute en una elevada presencia de población dependiente. La «Encuesta sobre Discapacidades, Autonomía Personal y Situaciones de Dependencia» de 2008 indica que existen 3,8 millones de personas con alguna discapacidad, lo que supone el 8,5\% de la población. Remitiéndonos al colectivo de más de 65 años, las cifras indican que el 30,5\% de las personas mayores poseen algún tipo de discapacidad que está asociada a una dependencia en un 21,6\%. Es decir, al menos un cuarto de las personas de más de 65 años son dependientes y necesitan de la ayuda de una tercera persona para realizar las actividades básicas de la vida diaria ${ }^{4}$.

Si ponemos estos datos en relación con la oferta pública de servicios sociales destinados a cubrir las situaciones de dependencia, encontramos una auténtica escasez de cobertura en la protección social. Las principales fórmulas de asistencia personal desarrolladas desde la Administración (es decir, las residencias gerontológicas, el servicio de ayuda a domicilio, la teleasistencia y los centros de día) presentan un índice de cobertura de un 12,1 \% (Sancho, 2007). Es decir, tan solo doce de cada cien mayores son usuarios de un servicio público.

Con estas cifras ya se intuye que la familia se convierte en la institución protagonista en la provisión de cuidado y asistencia de las personas de edad. En unos casos es la única proveedora de la atención, y en aquellos en los que existe un apoyo de los poderes públicos, éstos tienen un papel

4. Estas actividades están consideradas en todas las tablas que se presentan en este apartado son: lavarse, cuidados de las partes del cuerpo, higiene personal relacionada con la micción, higiene personal relacionada con la defecación, higiene personal relacionada con la menstruación, vestirse y desvestirse, comer y beber, cuidado de la propia salud: cumplir las prescripciones médicas, cuidado de la propia salud: evitar situaciones de peligro, adquisición de bienes y servicios, preparar comidas, realizar las tareas del hogar, cambiar las posturas corporales básicas, mantener la posición del cuerpo, desplazarse dentro del hogar, desplazarse fuera del hogar, uso intencionado de los sentidos (mirar, escuchar ...) y realizar tareas sencillas. 
complementario. El respaldo familiar es el colchón que amortigua las incontingencias de nuestros mayores. Aún en el caso de las personas que poseen ayuda de algún servicio social para afrontar la merma de sus capacidades, éste siempre necesita de una red de apoyo informal que permita el desarrollo adecuado de los programas de rehabilitación y mantenimiento (excepto en el caso de las residencias en donde acuden los mayores que no tienen familiares que los cuiden).

Legislativamente la Constitución reconoce el papel fundamental que deben cumplir las familias en la asistencia a personas dependientes, a pesar, de que también tiene que desarrollarse una red de servicios sociales que permitan el adecuado cuidado de este colectivo (artículos 41 y 50). Actualmente el conflicto de las familias con este aparato legislativo surge desde el momento en que se producen transformaciones familiares que han repercutido en la estructura del «trabajo de cuidados» dentro del hogar. El progresivo envejecimiento de la población, la incorporación de la mujer al mercado laboral y el paso de las familias extensas a las nucleares, ha generado que dentro de los hogares confluyan nuevas expectativas y roles que son incompatibles con los desempeñados antaño.

La escasez de un mercado privado de cuidados profesionales que sea flexible y económico ha repercutido en que las familias españolas hayan decidido externalizar la atención de los mayores hacia el servicio doméstico. Este sector proporciona tanto cuidados personales como ayuda para el mantenimiento del hogar, de tal manera que, en los últimos años esta opción se ha convertido en la principal vía de privatización. Los datos del IMSERSO (2004) confirman que, si bien, el 83,5\% de las familias cuidan sin ninguna ayuda adicional ni pública ni privada de sus mayores, lo cierto, es que cuando deciden subcontratar este trabajo familiar, la principal vía es emplear a una trabajadora domestica, que en la mayoría de los casos es una mujer inmigrante.

«¿Por qué? Porque las dos hermanas que estábamos aquí en Pamplona estábamos trabajando y entonces no disponíamos de tiempo suficiente para cuidar a nuestro padre que no se podía quedar solo. Estaba todo el día ya que se le iba un poco la cabeza. Aunque se manejaba él pero... solo no podía estar. Entonces era para cubrir las horas que nosotras no podíamos estar y bueno...» (Mujer contratadora de una cuidadora inmigrante, Pamplona, 2004) «Bueno, pues porque mi madre estaba muy bien y ella sola en el pueblo, y la encontramos muy mal. Una mañana que no la veía ni la encontraba y bueno, [...] decidimos que al vivir sola tenía que haber alguien con ella. Resulta que le había dado una trombo y se encontraba ya muy mal, en un estado muy crítico. ¿Cómo decidimos? Pues ninguno vivíamos en el pueblo. Todos estábamos fuera, todos trabajando, todos con hijos.» (Mujer contratadora de una cuidadora inmigrante, Pamplona, 2004) 
«Contratamos a una persona extranjera para cuidar de mi madre porque yo no podía atenderla durante el día. Me dijeron que no había españolas para hacer el trabajo. Tengo una librería y estoy todo el día fuera de casa. Ya sabes que una librería es muy atado porque tengo que abrir todos los días de la semana, sábados y domingos. Mi marido también trabaja y mis hijos, cada uno tiene su trabajo. Cuando mi madre empeoró y me la traje a mi casa se me echó el mundo encima. No era capaz de hacer todo el trabajo. Al final decidí contratar a alguien y las únicas personas dispuestas eran inmigrantes.» (Mujer contratadora de una cuidadora inmigrante, La Coruña, 2003)

Esta decisión, todavía minoritaria entre la población nativa, ha repercutido ampliamente en el mercado laboral del colectivo extranjero, llegando incluso a convertirse en el primer trabajo que encuentran las mujeres inmigrantes recién llegadas (Martínez Buján, 2008). La mayor vulnerabilidad de este colectivo, en muchos casos irregular, provoca que puedan acentuarse las situaciones de abuso y de explotación. Sólo adentrándonos en las características laborales de este sector de asistencia podremos deducir las verdaderas implicaciones de esta actividad sobre las cuidadoras y los receptores del cuidado.

\section{Los beneficios de las cuidadoras domésticas}

La preferencia de las familias por la contratación de cuidadoras en el seno del servicio doméstico está en gran parte determinada por las características laborales de este sector, que permiten una mayor flexibilización de horarios, una adecuación entre el tiempo de atención y el desarrollo de las tareas domésticas y la presencia, mediante la «modalidad de interna», de una cuidadora permanente que esté pendiente de las necesidades del mayor durante las 24 horas diarias. La oferta de provisión de cuidados por empresas privadas tiene un coste económico tan elevado que pocos presupuestos familiares pueden soportarlo. Además, la frecuencia y el tiempo de asistencia que ofrecen no alcanzan a cubrir las necesidades de la población dependiente.

El tiempo medio de atención diario suministrado por las familias es de once horas y la duración del cuidado tiene una media de seis años (INE, 2000). Teniendo en cuenta estas cifras, es lógico pensar que la familia necesite una cuidadora que dispense una asistencia continuada incluso durante la noche. Las familias empleadoras requieren una persona que realice tareas que van más allá de la atención personal al mayor: desde un «trabajo físico» como es la limpieza del hogar y los cuidados personales a un «trabajo emocional» que supone la presencia continúa de una persona que ofrezca con su compañía bienestar y cariño. Y esta tarea no es realizada desde las empresas privadas, cuyas cuidadoras únicamente se dedican a tareas específicas de asistencia personal. 
«Yo las cogía (se refiere a las cuidadoras) a través de agencia y ellas se dedican al cuidado de personas mayores y entonces: "No se preocupe porque nunca le va a faltar una persona". Al principio por eso decidí hacerlo por agencia. El salario pues se notaba, es más gravoso, pero era parecido el salario porque era el mismo, lo que pasaba que una me cubría siete horas y la otra todo el día. Y yo por el salario siempre me he regido por las normas de la asociación que eran las mismas para el empleo doméstico en España.» (Mujer contratadora de una cuidadora inmigrante, Pamplona, 2004)

«Una persona de aquí que te haga ese trabajo no hay nadie. Sé que hay algunas empresas que hacen unos turnos de mañana, tarde y noche pero eso es carísimo. Estábamos hablando de 400000 ó 500000 pesetas todos los meses. Y no hay quien mantenga eso. Y entonces a partir de eso con lo que había ya en ese momento ya se planteó coger a una persona de fuera.» (Mujer contratadora de una cuidadora inmigrante, Pamplona, 2004)

«Es que las de aquí -la entrevistada se refiere a las mujeres españolas- cobran carísimo. Nosotros pagamos a esta chica, 570 euros. Está mantenida y asegurada. Y aquí te dicen, 600 euros de día y 750 de noche. O sea, que te salen carísimas.» (Mujer contratadora de un cuidadora inmigrante, La Coruña, 2003)

La tesis doctoral de Sonia Parèlla Rubio (2003) en la que se realiza un análisis de las empresas de proximidad dedicadas a prestar servicios de atención personal y domésticos (dirigidos a personas dependientes) representa una útil fuente de datos a partir de la cual se pueden comparar las experiencias empresariales y las de empleadas de hogar en torno a este ámbito. La autora refleja cómo las familias que han decidido contratar el trabajo de cuidados a través del mercado formal privado lo han hecho como una segunda opción frente a experiencias negativas anteriores con una empleada doméstica. Otro de los motivos aducidos es la ausencia de una red de «contactos personales» que permita contratar a una persona «de confianza» en el hogar. Además, en estos casos, «el cliente o usuario contrata un servicio y no una persona (es la empresa y no el particular quien posee la condición jurídica de empleador)» siendo ésta otra de las ventajas «por cuanto ello ofrece al cliente la garantía de que siempre va a contar con alguien que cubra el servicio, con independencia de las circunstancias personales de la trabajadora» (Parèlla, 2003: 313).

Incluso así, la mayoría de las familias españolas que deciden externalizar el trabajo de cuidados lo hacen principalmente hacia empleadas domésticas debido a las elevadas ventajas económicas, al mayor tiempo de atención dispensado y a que el tipo de tareas que estas personas ofrecen no se limitan únicamente a los cuidados personales, sino que también engloba actividades relacionadas con el mantenimiento doméstico. Por un lado, las relaciones de dominación y explotación que pueden realizarse dentro del dominio privado representan, sin duda, una ventaja (Ungerson, 1999; Stefoni, 2002). Y por 
otro, la garantía que ofrece el ámbito empresarial en la realización de un seguimiento y evaluación de la trabajadora no está ausente en el caso de la contratación individual de una empleada de hogar, principalmente, si ésta se ha realizado por medio de una asociación. Aquellas instituciones con bolsa de empleo para cuidadoras actúan como verdaderos agentes responsables de la relación contractual tanto hacia la empleada como hacia la familia empleadora intentando ejercer de mediadores en caso de conflicto o descontento por alguna de las partes (Martínez Buján, 2006).

Estos beneficios en la contratación de empleadas de hogar para el trabajo de cuidados son vistos por algunos gerentes, siguiendo el trabajo de Parèlla, como una «competencia desleal» por los bajos precios que pueden llegar a ofrecer las familias empleadoras y por la creciente internacionalización del trabajo que ha puesto un ejército de reserva formado por mujeres inmigrantes capaces de aceptar condiciones laborales que rozan el «servilismo». El incumplimiento de la Administración en las tareas de asistencia personal fomenta la extensión del sector de cuidados privado. Este mercado de asistencia se ha modelado en nuestro país a partir del servicio doméstico y, en el actual contexto de migración internacional, se ha convertido en un nicho laboral para las mujeres inmigrantes. La flexibilidad de las condiciones de trabajo, la irregularidad y los bajos salarios determinan la necesidad de que un colectivo vulnerable se incorpore a esta actividad, requiriendo este trabajo una empleada que pueda ofrecer bienestar y asistencia.

\section{Actividades desempeñadas por las cuidadoras en los hogares}

En el sector doméstico de cuidados es común que la atención personal de los ancianos se combine con las actividades de limpieza y mantenimiento del hogar. Al ser un trabajo realizado en el interior del domicilio, las cuidadoras de ancianos, no son solamente eso, sino que se convierten en "chicas para todo». Esta situación es especialmente importante en el régimen de interna. El 89,4\% de las cuidadoras entrevistadas en el estudio «Empleados de Hogar. Apoyo a Mayores» (IMSERSO, 2004) asegura que la realización de las tareas domésticas (limpiar, planchar, cocinar...) forma parte de su trabajo junto con la asistencia y cuidados. Ello repercute en la invisibilización de su trabajo como cuidadoras, en la escasa valoración del mismo y en la asimilación del acto de cuidado como una mera actividad doméstica más. La limpieza y la toma de contacto con el anciano se hacen al mismo tiempo. Bañar al mayor, responsabilizarse de las medicinas, acompañarlo al médico e ir con él a dar un paseo para que recupere algo de su movilidad, son las actividades más sencillas que ha de realizar una cuidadora. La incontinencia fecal y urinaria y la vigilancia 
nocturna del anciano, son los aspectos más duros que se tienen que afrontar en este empleo.

«En Colombia tú trabajas de enfermera y es solamente para cuidar a la persona. Solamente tú te dedicas al paciente. Si hay que ponerle unas inyecciones, si hay que ponerle suero, si hay que estar pendiente de las medicinas, solamente del paciente. Aquí viene una chica, una señora que es la que hace el aseo general, pero yo a diario me levanto a las 9:00 de la mañana, aspiro, luego le hago un jugo de naranja a ella, luego ella se levanta, la visto, ella ya camina un poco, pero está muy mal.» (Cuidadora colombiana, La Coruña, 2003)

«También limpio la casa. Porque aquí va incluido eso también. En el momento en que no estás cuidando a la persona estás haciendo algo.» (Cuidadora brasileña, La Coruña, 2003)

«Les ayudo a bañarse, les baño, pero con la una, con la mayor, es la más ágil, está mucho mejor en sus facultades mentales, es más cuerda, está más lúcida... Ella se da cuenta de todo, ella no necesita otra persona más que, por ejemplo, lo que yo le hago. La comida, le ayudo al aseo, la ropa limpia, la ropa planchada, a la otra sí tengo que bañarle todos los días, tengo que cambiarle la ropa, usa pañal a la noche, bueno, las dos las tengo con pañal, porque si no es terrible. La casa, cuando llegué, es fatal. Está terrible. Tuve que empezar a limpiar, a hacer todo. Las cosas de casa también. Es un trabajo bastante fuerte.» (E7, cuidadora ecuatoriana, La Coruña, 2003)

«Y claro, dirán: "Esta señora no va a venir a cuidar solo a mi padre" y entonces también les limpio la casa.» (Cuidadora venezolana, La Coruña, 2003)

El cuidado de personas mayores es una actividad con unas características propias que difieren de las encontradas en las tareas relacionadas con la limpieza del hogar e incluso también divergen de las tareas de atención a niños. El «cuidado de ancianos» amplía y extiende las actividades que clásicamente desempeñaban las «sirvientas». A la limpieza del hogar se suman las de vigilancia y asistencia de los miembros más mayores. Ello supone tener bajo control la vida de personas a las que es necesario atender no únicamente desde el punto de vista físico. La asistencia pasa por la comprensión, el cariño y la compañía. A las duras tareas de atención personal relacionadas con el aseo, la movilidad, el suministro de medicamentos y la vigilancia nocturna también se añaden actividades emocionales conducentes a mantener el bienestar psicológico del enfermo anciano.

«Tienes que tener mucha humanidad. Hoy no he dormido, porque hay noches que quiere ir al baño y no quiere la cuña, quería ir al baño y en el baño me tuvo media hora sentada, media hora. Y otros dirán, que fatal, no se duerme, que mal. Pero yo digo, éste es mi trabajo y qué le voy a hacer.» (E8, cuidadora ecuatoriana, La Coruña, 2003)

«Arrimamos la cama al ropero, y nos acostamos nosotros, por ejemplo, en el suelo. Nos acostamos al lado de ella para ver... si rueda, rueda, y si cae lo hace 
encima de nosotros pero nos damos cuenta de que cae. A veces, quiere levantarse y yo estoy ahí y le digo: "Duerme, duerme, no te preocupes". Dormimos así más tranquilos, a pesar de que se levanta y nos llama...» (Cuidadora ecuatoriana, La Coruña, 2003)

«Era psicópata depresiva. Era terrible, terrible. Pensaba en suicidio, suicidio, suicidio, está en un cuarto oscuro y estuve tres meses para levantarla de la cama y que fuera a la calle, para pasear, para andar. Tres meses, pero hacía tres años que estaba en la cama en un cuarto oscuro. Tenía asistente social, psiquiatra, todos trabajando juntos, un día tiró ella de la cama, y un día me llama: "María, estoy fatal", "¿Qué fue?", "Sale un poquito". Y ella se anima y sale. Tiene manía ahora conmigo. Para mí fue terrible. Yo tenía miedo de salir un día de aquí, llegar allí y encontrarla muerta. Fue terrible (...). Ella sigue aún con tratamiento.» (Cuidadora brasileña, La Coruña, 2003)»

«Pero la señora desvariaba un poco de la depresión y después tuvo una trombosis, siempre se caía. La casa era pequeña y había poco que limpiar y la señora no era difícil, sólo había que cocinar unas verduras y pasar, hacer unas papas con leche y un poco de café y galletas y la ayudaba a sentar y a comer sola. Ella misma comía sola. Y darle la medicina. La responsabilidad era darle la medicina, el horario era a las diez de la mañana... Siempre buscaba alguna cosa para que hiciese ella misma, peinarse los cabellos, pintarse... Ella no podía salir de casa porque se caía. No tenía una silla de ruedas. Ella sólo salía de la cama y se sentaba en el sillón. Tomaba muchísimos medicamentos para la depresión: siete comprimidos por la mañana, siete al mediodía, por la noche no sé si era menos, eran cinco.» (Cuidadora brasileña, La Coruña, 2003)

En el cuidado de niños la tarea emocional se considera más ligera psicológicamente, ya que se trata de personas con vitalidad y fuerza dinámica, de la cual carecen los mayores.

«Con niños es más gratificante trabajar. Es mucho más gratificante. Con ellos vives cada día. Con los ancianos tienes que tener una paciencia enorme. Tienes que tener una paciencia increíble. Tú ves que a diario van a menos. Un niño va a más. Porque van enseñando y todo toman, todo cogen. Entonces eso para ti es un estímulo y le enseñé esto... En cambio, el anciano va a menos. Cada día va a menos, tienes que ayudarle más, ves que va perdiendo las facultades, le ves que te necesita.» (Cuidadora ecuatoriana, La Coruña, 2003)

La trabajadora debe mantener una posición conversadora, de comprensión y de ánimo ante personas que quizá pierdan la vida en poco tiempo. Las cuidadoras entrevistadas afirman que uno de los mayores problemas de las personas receptoras de asistencia es el grado de depresión en el se encuentran, originado no únicamente por motivos de salud, sino también personales, que en muchos casos son agudizados por ciertos medicamentos. Las enfermedades, las patologías irreversibles, los medicamentos, influyen en el estado de ánimo de los mayores y en sus alteraciones de carácter. 
«Pero que una persona también que está muy malita, y ya uno tiene que ver con eso, que aunque tengan caprichos, uno sabe que es a través de su enfermedad o de sus cosas porque las personas enfermas siempre se aburren. Hay días que están muy a gusto, pero hay días que también... bueno, hay momentos en que están enfermas, pero dices, como fastidian... Cuando uno está malo no quiere ni que les toquen ni que les vayan a hablar, que le vayas a decir nada, pero...» (Cuidadora dominicana, La Coruña, 2003)

«Necesita, esa señora, necesita de mucho cariño, porque los hijos no pueden estar todo el tiempo con ella y ella lo que necesita es estar acompañada, no tanto los cuidados. Ella me llama y me dice que soy su ángel, que soy su... me dice que le toque con la mano en el lado izquierdo, y yo ojalá que con tocarla fuera suficiente, que le pase el dolor.» (Cuidadora ecuatoriana, La Coruña, 2003)

El esfuerzo físico y la implicación que suponen la custodia continua del mayor repercuten en el estado anímico de la cuidadora, sobre todo, si trabaja de interna. Como es bien conocido, y otros estudios han recalcado, el cansancio psicológico es un referente continúo en las mujeres que trabajan como internas en el servicio doméstico (Oso, 1998). Pero este agotamiento psicológico se agrava aún más cuando se añade el cuidado de una persona mayor, debido, precisamente, al mayor esfuerzo y dedicación que tienen que prestar.

«Y el otro ya te digo, se cuidaba prácticamente solo, pero a él había que darle más atención de... había que estar conversando con él... Claro, estás cansada, no te levantas con ánimos de nada, yo tenía que estar preguntándole: "Y cómo está, y cómo no sé qué". Y a veces ni me daban ganas de hablar y ya me ponía mala y: "Qué te pasa. Por qué estás así, por qué no me dices nada..." de verdad necesitas un poco de tiempo para relajarte y afrontar el día.» (Cuidadora ecuatoriana, Pamplona, 2004)

«Es que no puedo contar con mi tiempo para nada. Para nada. No soy dueña de mi tiempo, no puedo decir, hoy cojo y me voy, que me apetece hacer esto. No, no. Es imposible, no puedo [...] Sí, es terrible. Estoy empezando con un problema de varices, porque paso mucho tiempo de pie, y no duermo tranquila. Porque me da miedo[...]El cuidar a una señora no solamente implica emplear tu trabajo físico, implica psicológico... Claro, no es lo mismo que trabajar ocho horas y llegues a casa y te olvides de tu trabajo. No. Me importa mi trabajo. Cuentas con tu privacidad. Aquí no pasa eso, no puedes decir, estoy cansada de hacer esto. No puedes decir, bueno, estoy cansada y me acuesto. Todo el tiempo tienes que hacer algo, todo el tiempo que tienes que estar ahí, ahí y ahí. Hay gente mayor en el edificio que dicen: "es que si vienen acá tienen que trabajar, tienen que trabajar".» (Cuidadora ecuatoriana, La Coruña, 2003)

«Sí, es que uno se siente bien deprimida, psicológicamente se siente acabada. Se pasa todo el día sin poder decir nada, sin poder conversar, que si entra, que si sale, pero está cohibida de todas las cosas que dentro de la casa están. Si quieres poner música a un volumen más alto, no se puede. Ver a los 
programas de televisión que uno quiere, no se puede porque se tiene que ver lo que ella ve, lo que ella hace. Igual en la comida, tienes que comer lo que ella come y una está acostumbrada a otra comida.» (Cuidadora ecuatoriana, Pamplona, 2004)

La falta de espacio privado, de tiempo libre para relajarse y pensar en ella misma, la ausencia de un lugar propio que pueda «definir como suyo» agravan las circunstancias en las que se encuentra la inmigrante. El desarrollo vital y el trabajo pertenecen al mismo ámbito. No es posible separar lo que pertenece a tu propia vida de lo que es específico de tu ocupación. Ambos conceptos permanecen juntos, inseparables. No existe una definición del tiempo de tu jornada laboral, porque es todo el día. Estas horas no se pueden catalogar como extraordinarias, sino que es lo que la legislación denomina como «tiempo de presencia»: «Se trata de tiempos acordados entre el empleador y la trabajadora y que no se dedican a la realización de tareas domésticas habituales, sino de tareas que exijan poco esfuerzo, como abrir la puerta, coger el teléfono, etc.»(Martínez Veiga, 2004). Pero estas tareas no pueden ser definidas como de «poco esfuerzo» en la actividad del cuidado de ancianos. Levantarse por la noche, cuidar al anciano desvelado, suministrarle sus medicinas en horarios no «laborales», formarían parte del tiempo de presencia.

«A mí, a veces, cuando se me pone así... Todas las noches, por ejemplo, te llama. Y te llama, te llama, constantemente. Y no quiere nada, tan sólo verte. Ella por el día tampoco duerme. Tú estás cansada de la noche de no haber dormido, otro día atenderla más, porque se pone pesada... y es muy cansado.» (Cuidadora ecuatoriana, La Coruña, 2003)

«Entonces, al cuidar ancianos al principio mal porque la abuela se tiene que levantar todas las noches cada hora, o cada hora y media para ir al baño.» (Cuidadora colombiana, La Coruña, 2003)

«Las acuesto, las dejo, pero en la madrugada siempre me despierto a ver si respiran o no respiran. Porque como están viejitas, al menos ver si les pasa algo, o si puedes ayudarles o... llamar al médico o hacer algo. Unas dos veces me levanto a verles.» (Cuidadora ecuatoriana, La Coruña, 2003)

«No me dejaba dormir por las noches y me levantaba tres y cuatro veces a ver si se había orinado... Una vez me cansé: "Me hace levantar cada rato, así que si usted se orina le tendremos que poner pañales y yo me levantaré a las ocho de la mañana a darle el desayuno". De igual manera todo el día: arreglar la casa, hacer la comida, las cosas... Todo. La lavadora y todo. Entonces, se puso a llorar y me decía: "Eres una mala, chica mala, me tratas mal". Y le dije: "Usted verá". Porque era un suplicio levantarme, me acostaba a veces a las once de la noche, porque ella se acostaba a las nueve y yo arreglaba, estaba un rato despejada, pero a las once, once y media... A las dos de la mañana me llamaba, a las cuatro de la mañana me llamaba, a las seis, otra vez. Y a las ocho ya quería que le diese de desayunar porque la estoy matando del hambre. Entonces yo me levantaba cansadísima. O sea, es que para mí la noche, todo 
el día puedes estar sacando el aire como burro, pero por la noche yo tengo que descansar. Por suerte, se tranquilizó y no me molestaba a las noches.» (Cuidadora ecuatoriana, Pamplona, 2004)

En general, las cuidadoras han hecho un esfuerzo enorme por adaptarse a la situación laboral que les ha tocado desempeñar. En la encuesta del IMSERSO sobre empleadas de hogar cuidadoras de personas mayores (IMSERSO, 2004) se pidió a las personas entrevistadas (tanto españolas como extranjeras) que

Tabla 1. Tareas identificadas por las empleadas de hogar que cuidan mayores como las más costosas a realizar, 2004

\begin{tabular}{|l|c|}
\hline & $\begin{array}{c}\text { \% de personas que consideran } \\
\text { el desempeño de esa actividad } \\
\text { como más molesta* }\end{array}$ \\
\hline Acostarse/levantarse & 26,6 \\
\hline Cambiar pañales heces & 26,5 \\
\hline Utilizar el baño & 22,8 \\
\hline Bañarse/ducharse & 22,5 \\
\hline Moverse & 21 \\
\hline Andar por casa & 20, \\
\hline Administración dinero & 19,2 \\
\hline Salir/desplazarse & 18,9 \\
\hline Vestirse/desvertirse & 18,2 \\
\hline Ir al médico & 17,1 \\
\hline Asearse/arreglarse & 16,8 \\
\hline Otras tareas domésticas & 16,3 \\
\hline Utilizar el teléfono & 16,3 \\
\hline Gestiones & 16,3 \\
\hline Utilizar transporte público & 16,2 \\
\hline Abrochar los zapatos & 15,6 \\
\hline Cambiar pañales orina & 15,5 \\
\hline Dar medicación & 15,2 \\
\hline Preparar comidas & 14 \\
\hline Comer & 13,6 \\
\hline Hacer compras & 12,9 \\
\hline
\end{tabular}

Fuente: Elaboración propia a partir de IMSERSO, Empleados de Hogar. Apoyo a Mayores, Madrid, IMSERSO, 2004. Pregunta: «¿Podría indicarme, ahora, de todas las tareas que me ha dicho que realiza, cuáles son las que le resultan menos molestas?»

* La pregunta original de la encuesta estaba relacionada con indicar las actividades menos molestas. Sin embargo, por diferencia, teniendo en cuenta la base de respuestas, he calculado las personas a las que les resultaba la actividad más molesta. 
identificasen de entre una lista de actividades aquellas que considerasen más engorrosas de realizar. Las tareas que alcanzaron las puntuaciones más altas no han sobrepasado el $26 \%$ de las respuestas, lo que significa que el descontento no ha superado a un cuarto de la muestra. Las funciones menos agradecidas son las relacionadas con el cuidado personal del dependiente, principalmente, las vinculadas a aspectos que suponen un esfuerzo físico y/o asociadas a los elementos de intimidad personal del mayor. Destaca la dificultad que entraña el contacto íntimo que requieren algunos tipos de atención como el cambio de pañales en caso de incontinencia fecal o algunas actividades de movilidad como «acostarse/levantarse».

Por lo tanto, hacer la limpieza de la casa, la compra y todas aquellas tareas relacionadas con el mantenimiento del hogar y con la gestión, no se identifican como aspectos molestos a reseñar. La asistencia personal representa el trabajo más intenso de su jornada laboral y, por lo tanto, el más costoso a realizar.

Las entrevistas en profundidad realizadas a las cuidadoras inmigrantes recogen también situaciones de elevada carga laboral y escaso salario. En la Tabla 2 se resume cuál es el nivel de dependencia que sufren las personas de edad a las que cuidan las entrevistadas y qué tipo de enfermedades presentan. Los casos que más llaman la atención por el alto grado de vulnerabilidad son de aquellas cuidadoras (que estando trabajando como internas) tienen que hacer frente a la asistencia de más de un anciano. En general, se trata de casos de matrimonios mayores que han perdido la autonomía a causa de su avanzada edad (suelen sobrepasar los 80 años). Sin embargo, la mayor carga de cuidar a dos mayores no se traduce en un mejor salario mensual. Es el caso, por ejemplo, de Laura (E1), que con 410 euros se ocupa de la realización de la limpieza del hogar junto con la atención diaria de un matrimonio en en que el marido, de 86 años, padece Alzheimer, y la mujer, de 84, tiene un cáncer terminal. En la misma situación se encuentra E6, que hace frente al cuidado de una pareja de ancianos, ambos con dependencia severa, por un sueldo de 480 euros mensuales.

\section{Conclusiones}

La principal vía de privatización de la asistencia dirigida a personas mayores es el servicio doméstico. La empleada de hogar se erige como la figura principal en la dispensación de cuidados mercantilizados. Las ventajas que ofrece este recurso en cuanto a disponibilidad horaria y condiciones laborales son dos aspectos que inciden en su demanda junto con las deficiencias del sistema público de protección social. 


\begin{tabular}{|c|c|c|c|c|c|}
\hline 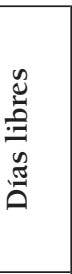 & 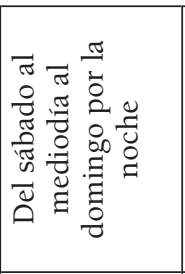 & 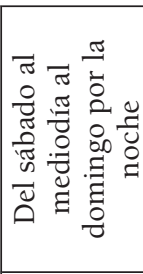 & 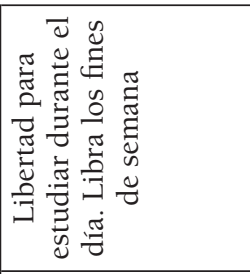 & & 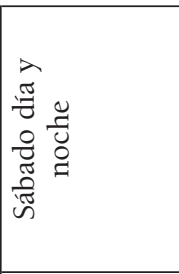 \\
\hline 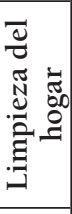 & is & $i n$ & 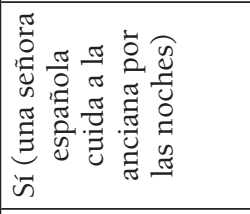 & $i \vec{n}$ & 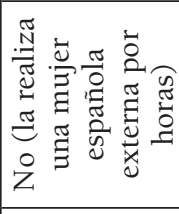 \\
\hline 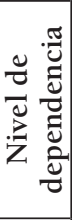 & 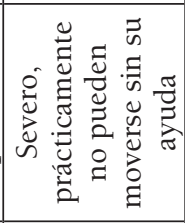 & 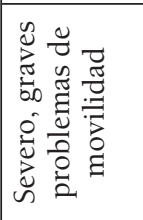 & 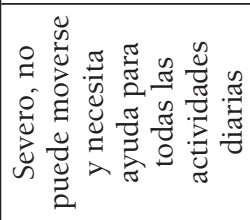 & 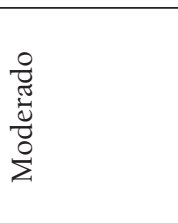 & $\begin{array}{l}\stackrel{0}{\sharp} \\
\grave{\sqcup}\end{array}$ \\
\hline 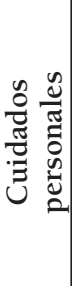 & 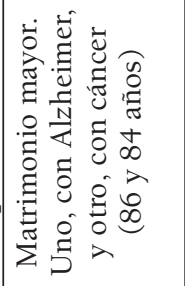 & 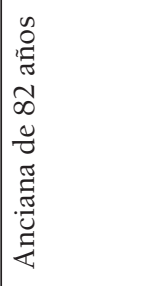 & 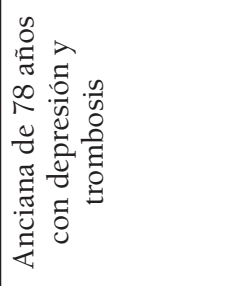 & 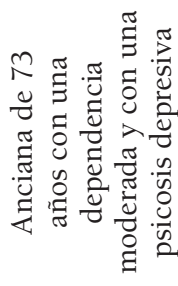 & 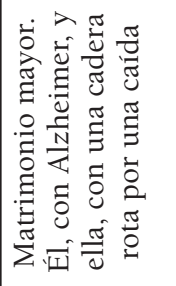 \\
\hline 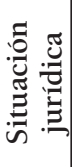 & 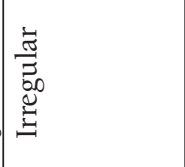 & 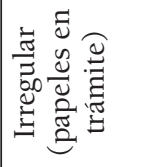 & 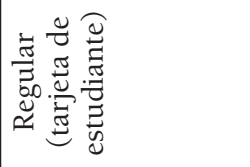 & 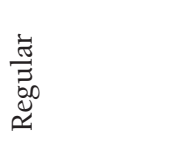 & 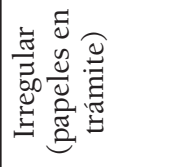 \\
\hline 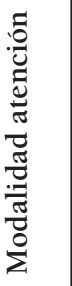 & 莺 & $\begin{array}{l}\stackrel{\Xi}{\Xi} \\
\stackrel{\Xi}{\Xi}\end{array}$ & 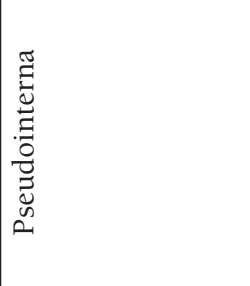 & 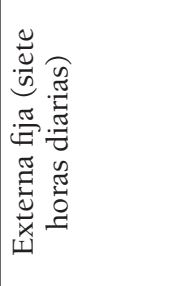 & $\begin{array}{l}\stackrel{\Xi}{\Xi} \\
\stackrel{\Xi}{\Xi}\end{array}$ \\
\hline 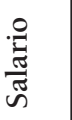 & 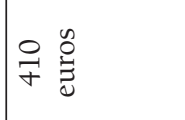 & in & : & ' & 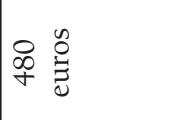 \\
\hline 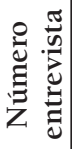 & 거 & & 㐫 & In & $\begin{array}{l}0 \\
\end{array}$ \\
\hline
\end{tabular}

Alternativas, 17, 2010, pp. 157-179 - ISSN 1133-0473 


\begin{tabular}{|c|c|c|c|c|c|c|}
\hline 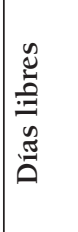 & 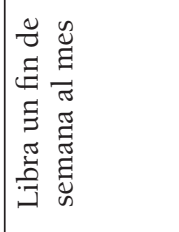 & 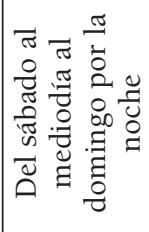 & 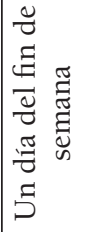 & 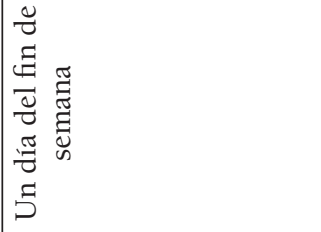 & 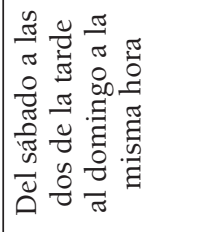 & \\
\hline 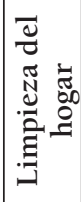 & is & $i n$ & $i n$ & $\stackrel{\circ}{Z}$ & 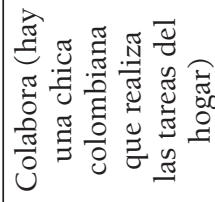 & in \\
\hline 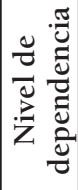 & 范 & 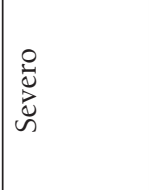 & 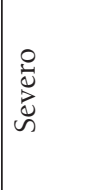 & 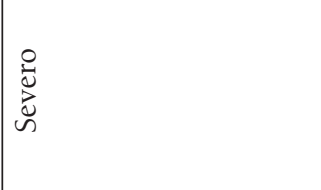 & 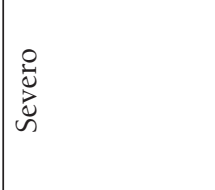 & $\begin{array}{l}0 \\
\frac{\pi}{\pi} \\
\frac{\pi}{4} \\
0 \\
0 \\
\Sigma\end{array}$ \\
\hline 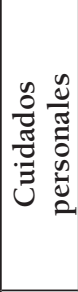 & 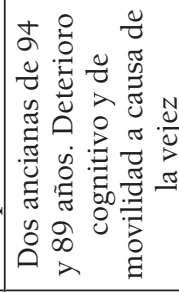 & 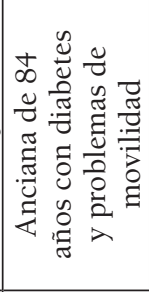 & 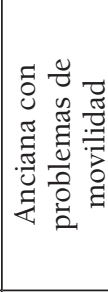 & 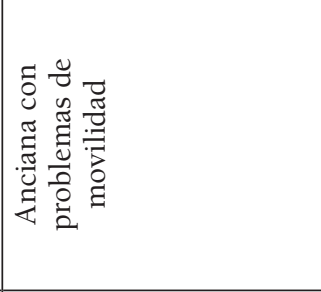 & 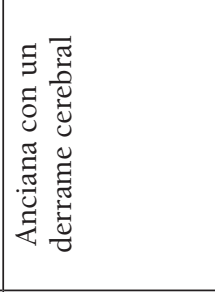 & 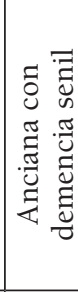 \\
\hline 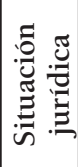 & 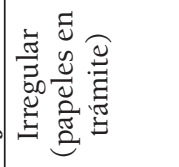 & 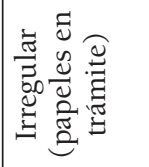 & 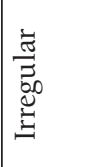 & 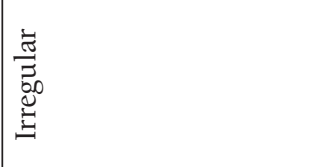 & 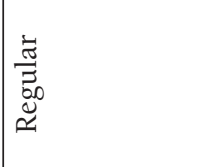 & 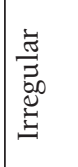 \\
\hline 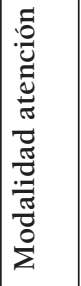 & 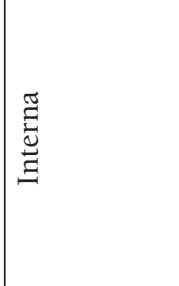 & 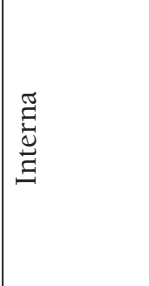 & 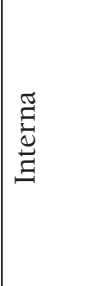 & 离 & 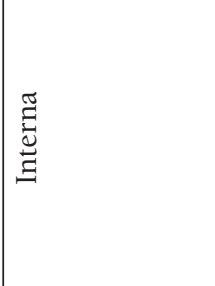 & 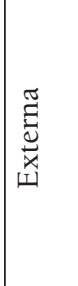 \\
\hline$\frac{\stackrel{9}{\pi}}{\frac{\pi}{\pi}}$ & 蛅 & 요 & 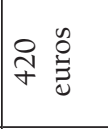 & 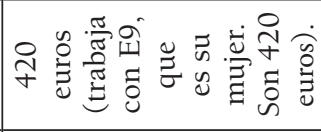 & 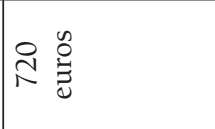 & \\
\hline 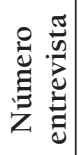 & 占 & $\begin{array}{l}\infty \\
1\end{array}$ & ્ㅣ & $\underset{\mid \overrightarrow{\mid}}{\stackrel{0}{2}}$ & $\vec{F}$ & $\underset{I}{\stackrel{\sim}{I}}$ \\
\hline
\end{tabular}

Alternativas, 17, 2010, pp. 157-179 - ISSN 1133-0473 


\begin{tabular}{|c|c|c|c|c|c|c|}
\hline 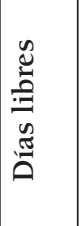 & 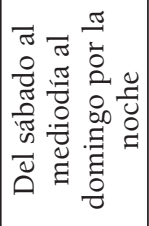 & 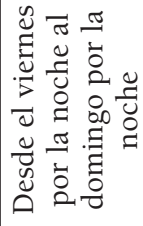 & & & 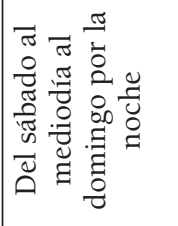 & \\
\hline 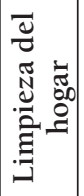 & in & $i n$ & $i n$ & 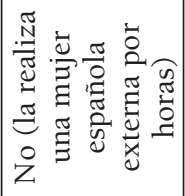 & 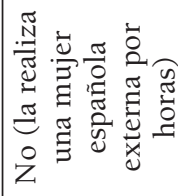 & \\
\hline 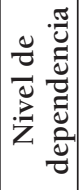 & O্் & 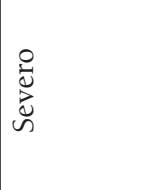 & $\begin{array}{l}0 \\
\frac{\pi}{\pi} \\
\frac{\tilde{U}}{0} \\
0 \\
\dot{0}\end{array}$ & 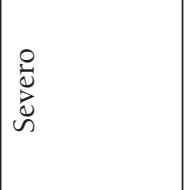 & & $\begin{array}{l}0 \\
\frac{\pi}{0} \\
\frac{0}{0} \\
\frac{0}{0} \\
\sum\end{array}$ \\
\hline 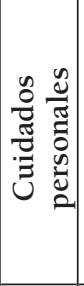 & 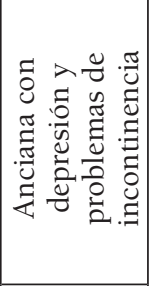 & 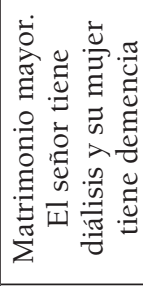 & 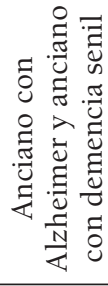 & 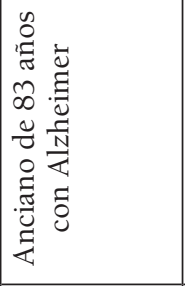 & 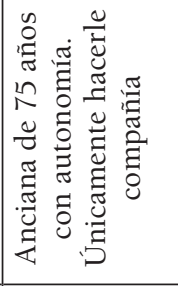 & 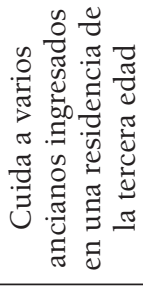 \\
\hline 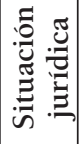 & 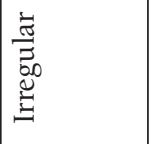 & 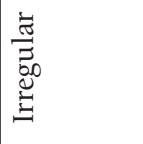 & 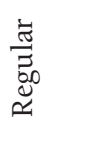 & 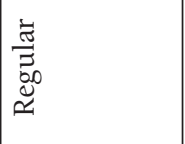 & 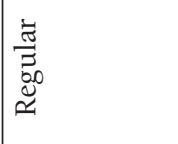 & 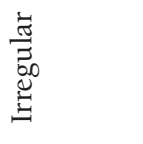 \\
\hline 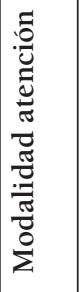 & 莺 & 蚫 & 莺 & 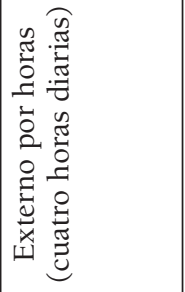 & 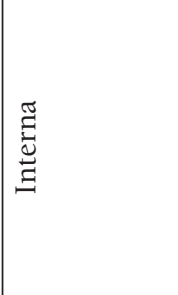 & 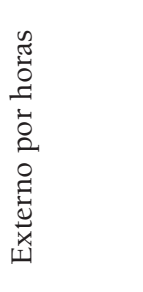 \\
\hline 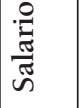 & in & 完 & $\overbrace{0}^{0} \stackrel{n}{0}$ & 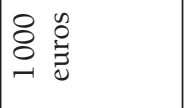 & : & \\
\hline 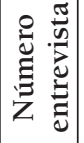 & $\frac{m}{\omega}$ & $\underset{I}{ \pm}$ & $\frac{10}{1-1}$ & $\begin{array}{l}\underset{\mid}{\sigma} \\
\dot{I}\end{array}$ & 검 & $\underset{|\sim|}{\infty}$ \\
\hline
\end{tabular}




\begin{tabular}{|c|c|c|c|c|c|c|}
\hline 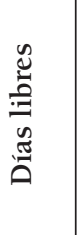 & 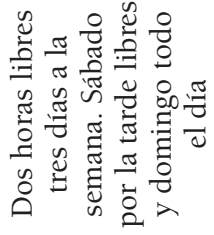 & 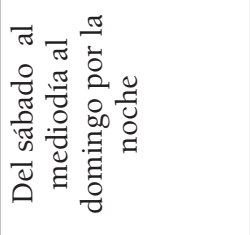 & 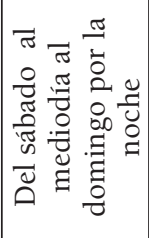 & 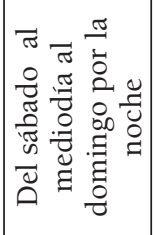 & 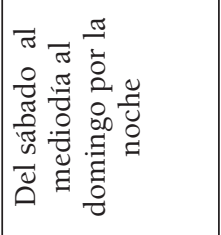 & ' \\
\hline 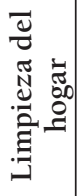 & in & $i n$ & $i \vec{n}$ & $i n$ & $i n$ & $\stackrel{\circ}{Z}$ \\
\hline 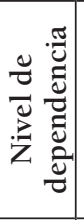 & : & 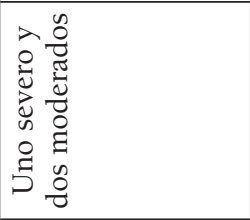 & 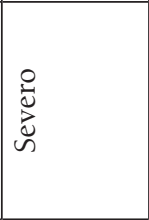 & 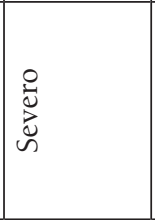 & 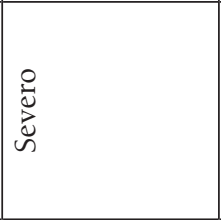 & 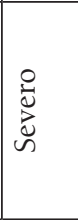 \\
\hline 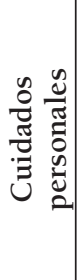 & 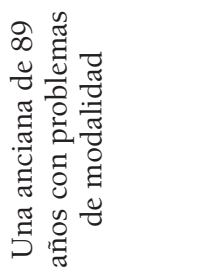 & 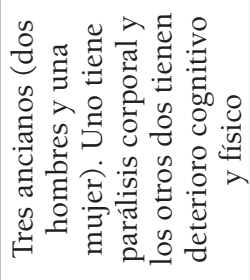 & 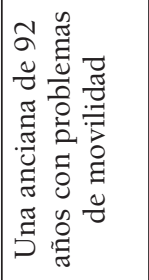 & 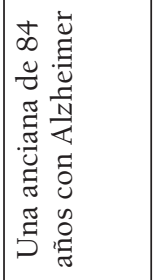 & 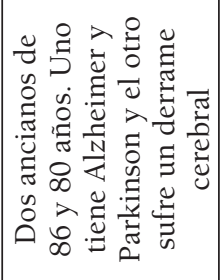 & 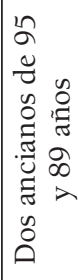 \\
\hline 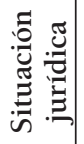 & 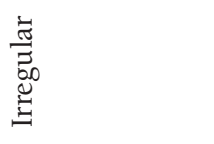 & 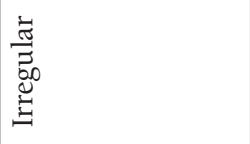 & $\begin{array}{l}\frac{\vec{\pi}}{\Xi} \\
\omega_{0} \\
\stackrel{\Xi}{\Xi}\end{array}$ & 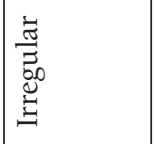 & 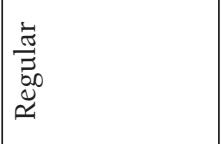 & 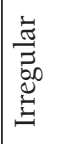 \\
\hline 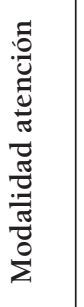 & 莺 & 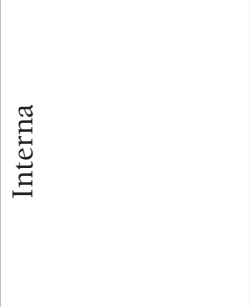 & 莺 & 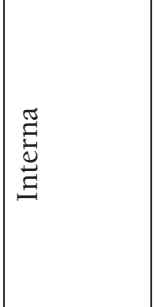 & $\begin{array}{l}\stackrel{\Xi}{0} \\
\stackrel{\Xi}{\Xi}\end{array}$ & 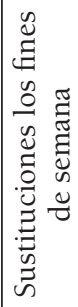 \\
\hline 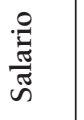 & ஓ & 号 & ஓ & ஓ & $\overbrace{0}^{0}$ & ' \\
\hline 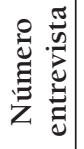 & $\underset{\mid}{\stackrel{\vartheta}{\mid}}$ & 오 & $\overrightarrow{\widetilde{I}}$ & 志 & $\underset{\sim}{\underset{\sim}{\sim}}$ & $\underset{\sim}{\stackrel{\sim}{\sim}}$ \\
\hline
\end{tabular}

Alternativas, 17,2010 , pp. 157-179 - ISSN 1133-0473 


\begin{tabular}{|c|c|c|c|c|c|c|}
\hline 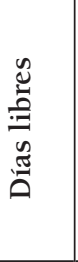 & 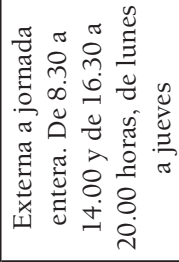 & 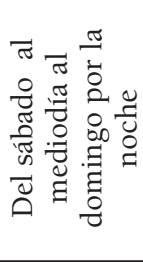 & 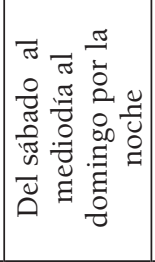 & 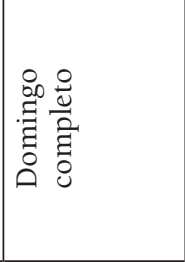 & 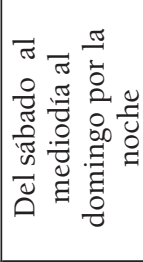 & 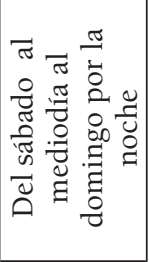 \\
\hline 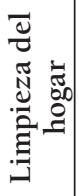 & is & in & in & 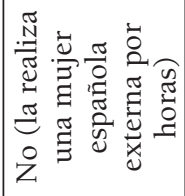 & $i n$ & $i n$ \\
\hline 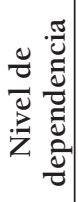 & : & 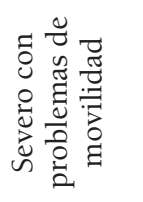 & 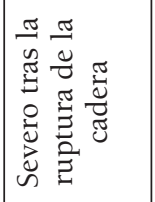 & 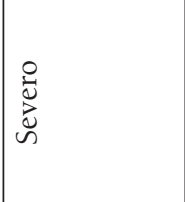 & $\begin{array}{l}0 \\
\frac{\pi}{0} \\
\frac{\pi}{0} \\
\frac{0}{0} \\
\Sigma \\
\Sigma\end{array}$ & 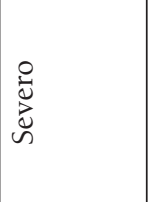 \\
\hline 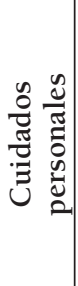 & 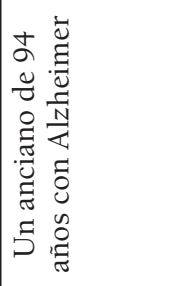 & 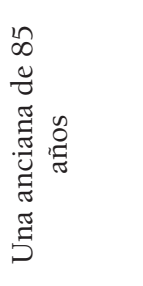 & 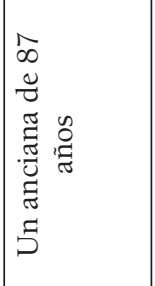 & 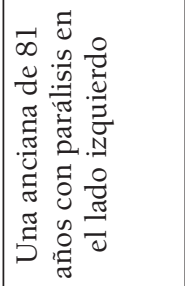 & 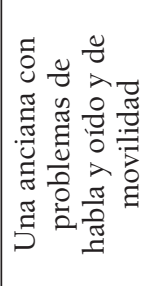 & 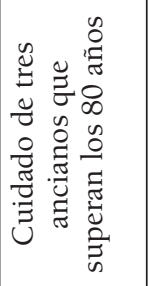 \\
\hline 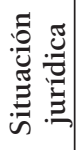 & 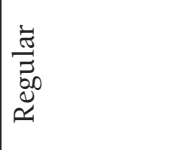 & 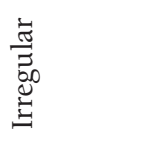 & 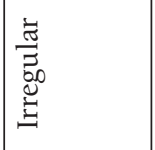 & 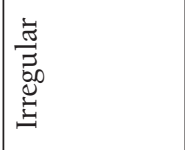 & 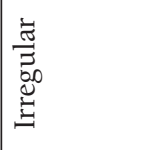 & 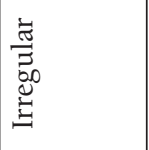 \\
\hline 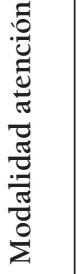 & 莺 & $\begin{array}{l}\stackrel{\widetilde{\Xi}}{\mathbb{U}} \\
\stackrel{\Xi}{\Xi}\end{array}$ & $\begin{array}{l}\text { 节 } \\
\stackrel{0}{\Xi}\end{array}$ & 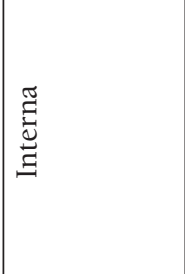 & 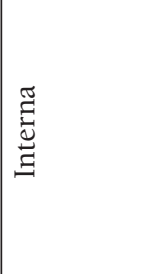 & 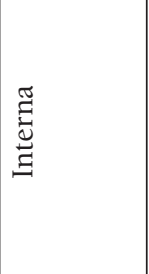 \\
\hline 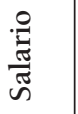 & $\bigotimes_{\infty} \stackrel{n}{\leftrightarrows}$ & $8 \stackrel{n}{:}$ & ஓ & ¿ & 呆先 & 尽哭 \\
\hline 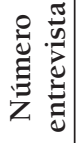 & $\stackrel{2}{\stackrel{1}{ \pm}}$ & 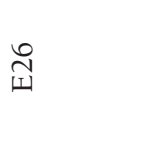 & 㐊 & $\underset{\sim}{\stackrel{\infty}{\sim}}$ & స્|ે & ભ્円ి \\
\hline
\end{tabular}


El proceso de internacionalización que está experimentando el mercado laboral español ha convertido este empleo en un verdadero nicho laboral para las personas inmigrantes. Este servicio de hogar destinado al cuidado de personas mayores se ha configurado para la mayoría de las mujeres extranjeras en el inicio de su trayectoria laboral en nuestro país. Consideradas como trabajadoras domésticas, la mayoría de ellas sin estabilidad jurídica, las necesidades asistenciales de las familias empleadoras se invisibilizan ante la ausencia de una red adecuada de servicios sociales. Al mismo tiempo se oculta la vulnerabilidad de estas trabajadoras bajo la frontera que marca la privacidad del hogar.

Los beneficios que estas cuidadoras ofrecen tanto para las familias españolas (promueven la conciliación laboral y familiar) como para la protección social (rellenan las debilidades de un sistema ineficaz de servicios sociales) desafían las políticas de control migratorio y muestran la clara incoherencia surgida entre las necesidades laborales de mano de obra flexible y la filosofía migratoria restrictiva de los países occidentales.

\section{Bibliografía}

FinOtelli, C., «Migration policy between restrictive purposes and structural demand: the case of the domestic sector in Germany and Italy», en Migration and Mobility in an enlarged Europe. A gender perspective, S. Metz-Göeckl, et al. (eds.), Opladen, Barbara Publishers, 2008.

IMSERSO, Empleados de Hogar. Apoyo a Mayores, [en línea], 2004, <http://www. imsersomayores.csic.es/estadisticas/ encuestas)>. Consulta: 30/09/2005].

INE, Encuesta de Discapacidades, Deficiencias y Estados de Salud, Madrid, INE, 2000.

- Encuesta de Discapacidades, Autonomía Personal y Situación de Dependencia 2008, Madrid, INE, 2009.

IZQUIERDO, A. et al., «The Favourites of the Twenty-First Century: Latin American Immigration in Spain», en Studi Emigrazione, n. ${ }^{\circ}$ 149, 2003, pp. 98-124.

LAPARRA, M., «Inmigración y política social en Europa», en Italian Journal of Social Policy (en prensa), 2008.

MARTíneZ BujÁN, R., «El cuidado de ancianos: un nicho laboral para mujeres inmigrantes y un reto de gestión para las entidades del Tercer Sector», en Revista Española del Tercer Sector, n. ${ }^{\circ} 4,2006$, pp. 145-173.

- «Envejecimiento, Mercado Laboral e Inmigración», en Revista del Instituto de Estudios Económicos, 2 y 3, 2008, pp. 65-85.

Martínez Veiga, U., Trabajadores invisibles. Precariedad, rotación y pobreza de la inmigración en España, Madrid, Catarata, 2004. 
Oso, L., La migración hacia España de mujeres jefas de hogar, Madrid, Instituto de la Mujer, 1998.

PARÉlla, S., Mujer, inmigrante y trabajadora: la triple discriminación, Barcelona, Anthropos, 2003.

SANCHO, M. et al., Informe 2006. Las personas mayores en España, Madrid, IMSERSO, 2007.

Stefoni, C., «Mujeres inmigrantes peruanas en Chile», en Papeles de Población, n. ${ }^{\circ} 33,2002$, pp. 118-145.

Ungerson, C., «Personal Assistants and Disabled People: an Examination of a Hybrid Form of Work and Care», en Work, Employment E Society, 13 (4), 1999 , pp. 583-600. 